\title{
O ORDINÁRIO E O ESPETÁCULO NO GOVERNO DA FRONTEIRA Normatividades de gênero em Tabatinga*
}

\section{Flávia Melo (1)}

https://orcid.org/0000-0002-3179-5294

\section{José Miguel Nieto Olivar}

(iD) https://orcid.org/000-0002-7648-7009

(1) Universidade de São Paulo (USP), São Paulo - SP, Brasil. E-mail: flaviamelodacunha@usp.br

(2) Universidade de São Paulo (USP), São Paulo - SP, Brasil. E-mail: escreve.ze@gmail.com

DOI: $10.1590 / 3410116 / 2019$

\section{Nas fronteiras de Tabatinga}

A proposta deste trabalho advém de uma experiência etnográfica prolongada e multiposicionada em campo. Entre 2011 e 2016, vivemos, lecionamos e pesquisamos na cidade de Tabatinga, tendo como perspectiva uma constante preocupação com as relaçóes de gênero: o campo acadêmico, os mercados do sexo, a presença peruana, as relaçóes interétnicas e as políticas públicas associadas a gênero, geração, sexualidades, segurança pública e à própria fronteira (Olivar, Melo da Cunha e Rosa, 2015; Melo, 2018).

* Flávia Melo teve apoio do Ministério da Educação (Edital Proext 2012-2016), Fapeam (PROPG) e Capes/PDSE (no 88881.187521/2018-01); José Miguel Olivar, da Fapesp (no 13/26826-2 e no 10/50077-1). Agradecemos as preciosas contribuiçóes de Fabio Candotti e dos pareceristas anônimos da $R B C S$.

Artigo recebido em: 16/11/2018

Aprovado em: 29/05/2019
Nesse período, testemunhamos mudanças nas políticas públicas e seus efeitos na vida social transfronteiriça. Principalmente, informados por uma perspectiva teórica de gênero, atentamos, testemunhamos e fomos partícipes das formas como "o Estado" e "a fronteira" se emaranham e são construídos e apropriados por redes locais afetivas, econômicas, sexuais e familiares. Assim, apresentamos aqui esse conhecimento forjado por duas experiências situadas num constante trânsito entre formas de governo ordinárias e espetaculares, que se imiscuem e se embaralham na vida social da fronteira e de seus agentes.

Esse propósito nos exigiu uma abordagem teórico-metodológica que nos permitisse perceber os processos de construção e transformação da fronteira e os trabalhos cotidianos de agentes que participam, em diferentes posições, da produção desse particular espaço performativo. Desse modo, o enfoque relacional e processual da proposta deman- 
dou um exercício atento de aproximação empírica com os espaços, as pessoas e as relaçóes.

Primeiro, apresentamos o fragmento de uma narrativa de relaçóes afetivas cotidianas, nas quais gênero, fronteira e Estado se intensificam mutuamente, de maneira interseccionada e corporificada. Essa narração da vida ordinária da/na fronteira sugere outra forma de pensar uma articulação na qual gênero não diz respeito apenas aos efeitos de uma política pública para as mulheres (mas a sistemas de relaçóes e a regimes normativos performativamente atualizados); e fronteira não diz respeito unicamente a processos organizados de expansão e expressáo masculina da soberania (mas a campos relacionais de diferenciação e conjunção). Na construção do argumento, transitamos - como fizemos durante todo o trabalho de campo - entre uma dimensão ordinária da vida transfronteiriça e a dimensão espetacularizada do governo soberano da fronteira.

Dessa perspectiva microssocial e micropolítica, nos movemos em outra direção e expomos os referenciais teóricos que norteiam a nossa descrição da cidade de Tabatinga, calcada na história colonial da região amazônica e no período anterior a 1980, valendo-nos da ideia de fronteira como "mito-conceito" (Serje, 2005) e das ideias de Wendy Brown (2010) e Veena Das (2007) sobre o Estado como um agenciamento masculino. Essa imagem nos serve de contraste para as transformaçôes históricas posteriores e para marcar os deslocamentos de perspectiva e de foco narrativo, nos quais gênero e mulheres começam a ter outro lugar político e analítico, tal como demonstraremos neste artigo. Nesse sentido, abordamos as transformaçóes da fronteira e das governamentalidades posteriores a $1980 \mathrm{em}$ termos de gênero: atentamos à participação das mulheres nesse processo e à vida social de políticas públicas que mobilizam a categoria mulher. A evidência da persistência - e das limitaçóes - de algumas narrativas mito-conceituais e do ponto de vista do Estado (como organismo centralizador) é a base para os deslocamentos teórico-metodológicos propostos no artigo, em que promovemos um diálogo cruzado entre antropologia, estudos feministas/de gênero e o campo dos estudos de fronteiras.

\section{Do governo ordinário da fronteira: cuidar da fronteira "desde abajo"1}

\author{
Já tinham chegado os soldados das Naçôes Unidas que \\ vinham vigiar o processo de paz. Chegaram com a \\ insolência de qualquer militar. \\ Eles, coitados, acreditavam ser donos de fronteiras, \\ capazes de \\ fabricar concórdias. \\ Mia Couto (2005, p. 10)
}

Quando Socorro, chorando, contou ao seu amigo Cauã que o dono do local do restaurante lhe pedira para entregar o imóvel em quinze dias, ele, furioso, se ofereceu para falar com o proprietário um grande comerciante local que lhe devia "alguns favores”. Não era a primeira vez que seus amigos lhe ofereciam cuidados. Mas, dessa vez, entendendo a dimensão dos favores e das dívidas, ela recusou o oferecimento. Assim, Socorro se preparou para desmanchar, em apenas duas semanas, o projeto que construíra durante quase dez anos.

Desde 2013, em Tabatinga, Socorro cuidava de Cauã como a um filho, alimentando-o. Esse era o eixo da relação entre eles: o restaurante dela. Mas não só. Socorro teve por todos aqueles anos uma empregada com quem construiu uma tensa e hierárquica relação de afeto e cuidado, de "quase" maternidade e trabalho. Flor trabalhou no restaurante como garçonete, como cozinheira e, algumas vezes, como administradora. Ela era jovem e muito desejada pelos homens que frequentavam o local. Flor namorou Cauâ, e foi nesse contexto que ele e Socorro se fizeram mais amigos.

Socorro, peruana da região serrana, é uma mulher independente e solteira, tinha uns 45 anos quando nos conhecemos. Chegou a Tabatinga sozinha, fugindo do seu contexto amoroso e familiar, e após uma tentativa fracassada de fazer negócios em Manaus. Na viagem de volta, de Manaus a Iquitos, decidiu ficar em Tabatinga. Negava-se a voltar à sua terra assim, "fracassada" e táo rapidamente. Aquela cidade lhe pareceu um lugar estratégico pela facilidade de ficar, fazer negócios e pela intensa conexão com o Peru.

Para muitos vizinhos peruanos e colombianos, "Brasil" e "la frontera" são referentes de melhor ou mais fácil acesso ao dinheiro, de maior liberdade 
sexual, de acesso à terra e a sistemas aparentemente superiores de garantia de direitos. No processo de municipalização e urbanização dos últimos trinta anos, a cidade de Tabatinga materializou essas possibilidades de um Brasil-na-fronteira, aberto a "estrangeiros", o que, para alguns brasileiros, resultava ser desigual e excessivamente permissivo (Olivar, Melo da Cunha e Rosa, 2015).

Como muitos e muitas peruanas em Tabatinga, Socorro entrou no negócio das comidas e, anos depois, conseguiu montar o próprio restaurante - muito bem-sucedido dentro da pequena e muito delimitada classe média local: pessoas brancas, brasileiras e colombianas, profissionais da área da saúde, professores universitários, militares das Forças Armadas, policiais federais, alguns comerciantes colombianos e brasileiros, principalmente homens. Seu talento para as relaçóes públicas e seu desejo insistente de diferenciar-se levaram-na a construir relaçóes de amizade com muitas dessas pessoas, como Cauã.

Homem na casa dos 25 anos, branco, "corpo malhado", oriundo do Sudeste do Brasil. Intenso, sincero, violento e "machista", nas palavras da própria Socorro, Cauã chamava a atenção por sua inteligência, sagacidade e pela ferocidade dos seus preconceitos. Era agente federal de segurança pública. Sua passagem pela cidade - parte da estratégia brasileira de controle policial/militar das fronteiras, das migraçóes e dos mercados transfronteiriços ilícitos (particularmente tráfico de drogas) - durou três anos, como serviço obrigatório da sua carreira, e implicou uma indenização adicional ao seu salário, elevando seus ganhos mensais equivalentes a, mais ou menos, dez vezes o que Flor poderia ganhar por mês e mais que o dobro dos ganhos de Socorro.

Cauã detestava peruanos e não escondia esse afeto. Em certas ocasióes, chegou a agredir verbalmente alguns "estrangeiros" durante a realização da burocracia migratória. Porém, sempre gostou de Socorro e criou com ela um vínculo de proteção bastante forte. Quando seus pais foram visitá-lo em Tabatinga, conheceram-na e ficaram encantados com ela, a quem nomearam representante da mãe nessa cidade, nessa fronteira que sentiam como tenebrosa, infernal e muito perigosa. Nessa relaçáo maternal, seu trabalho policial se desdobrava para a proteção e o cuidado de uma "estrangeira", escolhida a dedo e abraçada carinhosamente.

Essas relaçóes de afeto e cuidado, que incluíam altos oficiais, fizeram com que o processo da legalização de Socorro no "Brasil" (isto é, em Tabatinga) fosse mais célere, antes mesmo da entrada em vigor do acordo $\mathrm{Mercosul}^{2}$. O gênero, a classe, a posição de forasteiros em terras bárbaras e a desconexão dos parentescos de origem se encontravam ao redor dos cuidados e da alimentação para constituir determinadas imagens e relaçóes: eles confiavam nela, consideravam-na uma "boa peruana”, "diferente dos outros”. Estavam, então, dispostos a protegê-la, a lhe fazer confidências, a ouvir seus bons conselhos, a serem amigos. Para ela, essas relaçóes resultaram na mais firme proteção; amizades "apresentáveis" no seu contexto de origem; ingressos certos e clientela distinguida. No caso do Cauâ, esse tecido fino possibilitou primeiro o acesso - e depois a proteção e o cuidado - de sua particular fronteira: Flor.

Flor era jovem, pouco mais de 20 anos, divertida e considerada "muito bonita e atraente", tanto por Socorro como pelos clientes do restaurante que a miravam, falavam-lhe coisas, paqueravam-na. "Porém", "loretana", quase "índia", ribeirinha, com baixa escolaridade, "salvaje" e "sin aspiraciones en la vida". Nasceu numa pequena comunidade de Loreto, de onde partiu em busca do Brasil, num projeto migratório familiar e feminino. Flor era a mais jovem. Uma das familiares que a acompanhou nesse projeto, amante de um alto funcionário da cidade, era considerada a "puta" da família. Outra casou-se com um militar do policiamento fronteiriço e vive numa cidade nordestina. Mas Flor desprezava todos os homens que se aproximavam dela, recusou propostas de casamento financeiramente rentáveis de homens brasileiros e colombianos. Nesses anos, o único homem com quem teve uma relação mais intensa e duradoura foi Cauâ, quem menos coisas materiais lhe ofereceu.

Segundo Socorro, a relação tinha um componente forte e violentamente erótico, de combate, de domesticação mútua. Ela, afinal, era boa parte de tudo aquilo que ele desprezava naquele "cu do mundo" - e de tudo aquilo que teria gostado de possuir. Ela - a Flor, a tríplice fronteira, Tabatinga - foi a fronteira que penetrou e não conseguiu 
civilizar; aquela que ele e Socorro buscaram, fantasiaram, odiaram.

No início, Socorro incentivou a relação. Afinal, Cauã encarnava a possibilidade de a jovem deixar de ser "tan india", "salvaje" e "mejorar de vida". Ela favorecia encontros, mediava brigas, aconselhava Flor a polir suas maneiras. Mas a relação foi mudando e Socorro passou a cuidar mais dele. Inclusive, protegeu-o da fúria, "salvajadas" e "brujerías" de Flor. Enquanto a amizade e confiança com Cauã cresciam, a relação com Flor tomava maior distância e desconfiança. Nos últimos tempos da vida em Tabatinga, Socorro estava convencida de que era vítima de um feitiço. Evangélica batizada, buscou ajuda em terreiros para apurar as origens de seus problemas. Uma série de coincidências e conjecturas convenceram-na de que o feitiço havia sido feito por Flor, com a ajuda da mãe. Socorro chegou a ir a Iquitos para que uma famosa bruja desfizesse o tal feitiço. Ao final do ritual, a bruja sentenciou: "No te están haciendo daño, lo que pasa es que tú no sabes administrar tu negocio".

Como vimos, nesse sistema relacional intensamente afetivo, sexual e econômico, se produzia um conjunto ou sistema de fronteiras bastante fragmentado e emaranhado nas açóes mais ordinárias e cotidianas desses agentes. No intuito de alijar-nos das análises distanciadas e de grades interpretativas que privilegiam a "heroicidade", partimos da cotidianidade (Serje, 2005; Das, 2007; Moreno e Langdon, 2018), das relaçóes vivenciadas no cotidiano da fronteira para, imersos numa intriga tripartite, observar o agenciamento - não mais do Estado, como protagonista ou único produtor daquela fronteira, e tampouco de seus heróis ou vultos masculinizados, mas em formas de governo agenciadas por mulheres (e também por homens) em relaçóes cotidianas de comensalidade, parentesco, afeto e poder. Apostamos, pois, "na descida ao cotidiano, no preparo diário da alimentação, na arrumação e organização dos afazeres, no cuidado e cultivo persistente das relaçóes familiares" (Pereira, 2010, p. 363), onde nos foi possível observar, muito proficuamente, a produçâo performática e ordinária da fronteira e do gênero.

Nossa tríade de personagens pode ser, em certa medida, arquetípica. Cauã integra aquela centena de corpos masculinos fardados, armados e bem remunerados que circulam ostentosamente pela cidade de Tabatinga. Socorro e Flor fazem parte (ainda que em matizes muito distintos) do regime que produz a abjeção à presença peruana naquela região (Olivar, Melo da Cunha e Rosa, 2015), ao mesmo tempo são representativas de agenciamentos e processos de contradomesticação frequentemente invisibilizados nas abordagens macroestruturais que privilegiam o espetáculo em detrimento do cotidiano. Socorro, em seu esforço contínuo de distinguir-se dos seus conterrâneos, dedica-se justamente ao mesmo ofício de muitas outras mulheres e famílias peruanas da cidade; ao redor das mesas do seu restaurante, ela reúne seus novos familiares e amigos, intercambiando afetos, ajudas e confidências.

Flor - da perspectiva de Cauã e Socorro - materializa uma fronteira muito particular: jovem "índia", "bruja" e "salvaje", que corporificava o desejo de Cauã, a repulsa de Socorro e o medo de ambos. Suas constantes recusas aos pedidos de casamento não eram apenas movimentos contestatórios, mas tinham o efeito de desconstruir poderosas e persistentes discursividades que produzem e controlam a "indomável" sexualidade das mulheres amazônicas, que condenam a "ambição" das nativas e sua busca por casamentos "vantajosos" ou que denunciam a maternidade "oportunista" de "estrangeiras" em busca dos "cobiçados" benefícios sociais brasileiros (Campos, 2018).

Com ela, pouco conversamos. Sempre sorridente e prestativa, quase nunca nos permitia deslanchar na conversa. De Flor, jamais soubemos como se reconhecia etnicamente. Isso nunca foi um tema em nossos encontros e ela jamais se definiu, para nós, como indígena. Nas poucas conversas que nos permitiu participar ou observar - inclusive com suas irmãs -, sempre a ouvimos falar em espanhol ou português, e nenhuma outra das tantas línguas que escutamos naquela região. Isso não significa que Flor não reivindicasse pertencimento étnico, tampouco que esse era tema desimportante. Ao contrário, a discussão em torno da etnicidade de Flor teve importância fulcral nessa trama justamente pelo modo como essa mulher e seu corpo foram perspectivados e metaforizaram a fronteira para Cauã e Socorro, para quem Flor era "a índia".

Socorro, mulher peruana e migrante tal como 
Flor, insistia em marcar severamente a diferença entre elas: não índia versus índia, serrana versus loretana/amazônica, civilizada versus "salvaje”. Dedicando-se continuamente ao seu investimento de distinguir-se, enfatizava as diferenças entre a sua gente "serrana" e a gente da floresta (loretanos, por exemplo), assim reiterava uma "geografia moral $\mathrm{da}$ ordem colonial que subordina a selva ao lugar da queixa, do atraso e da incivilização" (Moreno e Langdon, 2018, p. 149).

Cauâ, por sua vez, situando Flor como "índia" e "peruana", nunca se referia a um possível pertencimento étnico, mas à sua "selvageria", "brutalidade" e "atraso". Todos os argumentos de Cauã e Socorro operavam, pois, no sentido de enquadrar Flor dessa forma, materializando em seu corpo e sexualidade uma parte do sistema de perigos da fronteira ${ }^{3}$.

"Índia", nas palavras de Socorro e Cauã, expressava uma marca de alteridade radical e uma concepção depreciativa arraigada a certa construção ambígua da "índia", ao mesmo tempo sem ambição ("sin aspiraciones en la vida") e invejosa (principal motivo alegado aos feitiços supostamente preparados por Flor e sua mãe $)^{4}$. Em seu estudo sobre a criação da mulher étnica estadunidense, Silvia Falquina (2003, p. 42), amparada em vasta bibliografia decolonial e antropológica, analisa justamente a construção da "índia" como derivação de "índio" - uma categoria sem referente, forjada num equívoco geográfico e inerente à discursividade de processos "neocolonizadores".

No contexto das relaçóes tabatinguenses, essa enunciação deve ser cotejada, ao menos, com dois outros elementos: a numerosa presença e participação de pessoas pertencentes a vários grupos étnicos cujos territórios foram atravessados pelos limites nacionais de Brasil, Peru e Colômbia ${ }^{5}$; e o fato de essa cidade e região serem forjadas em meio a duradouros processos coloniais e uma extensa e conflituosa história de contatos interétnicos.

\section{Do governo espetacular da fronteira: "el control desde arriba"}

Nos limites oficiais da geopolítica brasileira, a cidade de Tabatinga está situada no oeste do Estado do Amazonas (Brasil), à margem esquerda do rio Amazonas, com população estimada em 65.844 habitantes, distribuídos em 3.266 quilômetros quadrados de extensão territorial (IBGE, 2018). Teve origem num povoado formado nas adjacências do forte militar de São Francisco Xavier de Tabatinga, erguido na segunda metade do século XVIII por um destacamento militar, a fim de demarcar os territórios de Portugal e Espanha e dirimir as disputas territoriais entre os reinos (Zárate, 2008; Sampaio, 2009).

Entre o final do século XIX e os anos 1940, teve lugar, nessa região amazônica, a exploração transnacional da borracha, que promoveu a chegada de "soldados da borracha" (principalmente homens), vindos de diversas regióes do Brasil (sobretudo Nordeste), do Peru e da Colômbia. Essa economia, como explica Roberto Camacho (2011), mudou para sempre a paisagem e a vida social na Amazônia e marcou o processo de fronteirização interna e externa desses países. Assim, a cidade e a região transfronteiriça têm uma longa história de processos espetaculares de conquista e colonizaçóes com o protagonismo de corpos masculinos, militares e religiosos (Taussig, 1986; Zárate, 2008, 2011; Sampaio, 2009; Camacho, 2011), responsáveis por controlar, converter, "civilizar" e dizimar as populaçóes indígenas nativas. Do mesmo modo, a história da região é marcada por economias de extração de recursos naturais, de comércios informais através dos rios e da lógica da dívida (Taussig, 1986), que são marcantes até hoje.

Apesar do crescimento populacional e do surgimento de diversos povoados, comunidades e cidades, no marco dessas transformaçóes econômicas, a guarnição militar instalada no século XVIII manteve-se como uma vila militar a serviço da defesa fronteiriça até meados do século XX. Em 1968, durante a ditadura militar brasileira que se estendeu até 1985 , o território dos municípios fronteiriços foi classificado como "área de interesse da Segurança Nacional" ", o que exigia maior presença das instituiçóes de defesa nacional. Com essa preocupação, o povoado, até então dependente de outros mais antigos, tornou-se um município autônomo, sendo instalado efetivamente em 1983.

Nos anos 1960, a vila militar de Tabatinga constituía-se ainda como Pelotão Especial de Fron- 
teira, tal como outros postos instalados na Amazônia, formada quase exclusivamente por homens jovens e solteiros ${ }^{7}$, nordestinos, que se aventuravam na região pelo alistamento militar. À época, as Forças Armadas Brasileiras incentivaram a migração de recrutas para as fronteiras amazônicas oferecendo vantagens financeiras e previdenciárias aos que ali permanecessem.

$\mathrm{Na}$ história das famílias da região, é muito comum a união desses homens com mulheres nativas. A esse respeito, Adriana Marques (2007, p. 91) argumenta que a estratégia militar de povoamento e defesa das fronteiras amazônicas esteve fortemente associada a ideários de fixação e "miscigenação" e a práticas de reprodução sexual, incentivadas institucionalmente pelas Forças Armadas para a construção da "pátria". Essa descrição se multiplica facilmente nas crônicas de antigos habitantes de Tabatinga e de militares aposentados que ali trabalharam (Melo, 2019). Nas palavras de uma moradora: "aqui todo mundo é filho de militar".

Essas narrativas desenham as formas de governo constituintes da história recente da cidade e nos permitem ver como determinadas imaginaçóes sobre gênero, raça, Amazônia e fronteira se cruzam e articulam para constituir não apenas a ação do Estado, mas povoados, cidades, fluxos econômicos e princípios de relação social. O desbravamento da fronteira como um agenciamento masculino é resultado também de uma imaginação generificada, "imperial", sobre o corpo, o trabalho e o próprio território (McClintock, 2010). Essas relações, lógicas e imaginaçóes encontram estímulo em narrativas militares e religiosas e tiveram um fértil espaço de reprodução nas dinâmicas econômicas extrativistas.

Tais economias têm sido pensadas como fundamentalmente masculinas, requerentes de corpos forasteiros, e resultaram em importantes empreendimentos de fixação, reprodução e urbanização. Às empreitadas de fronteirização amazônica cabia a tarefa não de defender um território, mas de produzi-lo e povoá-lo em termos de uma muito específica organização de gênero que era reelaborada "lá", na correlação de forças, agências, saberes e possibilidades. Essa imagem da cidade, anterior aos anos 1980, é a imagem de contraste de nossa análise. Uma imagem constitutiva das grandes narrativas brasileiras sobre as fronteiras amazônicas internas e internacionais (Faulhaber, 2001; Becker, 2005).

Em meio à proliferação de análises sobre a polissemia da ideia de fronteira e a multiplicidade de abordagens ${ }^{8}$, a antropóloga colombiana Margarita Serje (2005) procura outro rumo a partir da ideia de "mito-conceito". A autora se debruça sobre o processo histórico, multidimensional e conceitual de construção dos "territórios selvagens", das fronteiras e periferias do Estado-Nação colombiano. Esse processo a leva a compreender a forte dimensão mítica, autorreprodutiva e mitificadora do conceito de fronteira, intimamente ligado à ideia de territórios vazios, de populaçóes selvagens e dos "héroes de la Frontera", um espaço ao mesmo tempo vazio e rico, fantástico e carente, produto de sistemáticas políticas de estetização e erotização dos outros. Na linha de Michael Taussig (1986), a autora demonstra como esse sistema imagético sobre a fronteira é atualizado contemporaneamente em termos de políticas públicas, notícias midiáticas, açôes humanitárias e até pesquisas sociais que tentam produzir informação sobre os confins da humanidade ou sobre as resistências de fronteira?.

Ainda que a fronteira priorizada por Serje para a sua conceitualização seja a interna (frontier), é possível estender parcialmente suas análises para a compreensão mítico-conceitual das fronteiras internacionais (borders and borderlands), principalmente na América do Sul. Essa extensão ganha sentido quando pensamos na Amazônia, onde fronteiras agrícolas e econômicas, coloniais, de conservação, étnicas e nacionais têm se sobreposto há séculos, e cuja construção mítica continua vigente e determinante até hoje. Seguindo o pensamento de Marshall Sahlins (1985) sobre a "atualização conjuntural das estruturas míticas”, as transformaçôes políticas recentes dos estados nacionais "atualizam" a lógica mito-conceitual que as estrutura. $\mathrm{O}$ mito-conceito da fronteira, afinal, é estruturante da imaginação política nacional (Serje, 2005; Nail, 2016). À continuação, mostramos como essa "estrutura na conjuntura" se atualiza nas mudanças políticas nacionais a partir dos anos 1980, resultando numa reorganização das relações de gênero.

A partir dos anos 1980, no marco da transição democrática brasileira, das novas constituiçóes de 
Colômbia (1991), Brasil (1988) Peru (1992), da expansão de políticas neoliberais, do crescimento do tráfico de cocaína na regiáo e da recente municipalizaçấo de Tabatinga e outras cidades brasileiras adjacentes, tem lugar nessa tríplice fronteira uma série de transformaçóes territoriais, políticas e econômicas. Tabatinga foi laboriosamente construída como uma unidade urbana (Aponte Motta, 2011), tendo como principal força de propulsão os recursos humanos e materiais das forças militares. Isso implicou a unificação de diversos territórios no Brasil: a vila militar de Tabatinga, a comunidade indígena Ticuna de Umariaçu ${ }^{10} \mathrm{e}$ as pequenas comunidades de colonos - inclusive peruanos -, organizadas na beira do rio ou nos limites internacionais com a Colômbia.

As noçōes territoriais brasileiras de "Faixa de Fronteira", "Arco Norte" e "Mesorregiáo amazônica do Alto Solimóes" são também centrais para a compreensão de Tabatinga. A definição legal de "faixa de fronteira" foi estabelecida em $1979^{11}$ e, três décadas depois, em 2009, incorporada à classificação territorial de "arco norte" do Programa de Promoçáo do Desenvolvimento da Faixa de Fronteira ${ }^{12}$. O Arco Norte englobaria - entre outras características que atualizam as narrativas mito-conceituais sobre a Amazônia - peculiaridades étnicas e administrativas, constituindo-se um "arco indígena", tanto do ponto de vista do território (presença de territórios indígenas) como da identidade territorial (importância étnico-cultural indígena mesmo fora das terras indígenas). Ao mesmo tempo, o programa integrou a Política Nacional de Desenvolvimento Regional (Decreto no 6.047/2007), que classificou o município de Tabatinga como pertencente à Mesorregiáo do Alto Solimốes ${ }^{13}$. Essa forma de classificação resultava de certa apropriaçáo de teorias de desenvolvimento regional e de conceitos como "desenvolvimento regional desigual” (Harvey, 2004, 2006) e supunha uma série de indicadores de "vulnerabilidade social" vinculados ao pensamento geopolítico brasileiro hegemônico (Sprandel, 2005).

Em 2008, um novo programa somou-se aos anteriores: o Territórios da Cidadania, estratégia de universalizaçáo de açôes para a cidadania implementada em regióes do país tidas como "mais vulneráveis" (Brasil, 2008, p. 2). Esse programa pro- punha articular uma série de políticas públicas em territórios, como a Mesorregiấo do Alto Solimóes e a Faixa de Fronteira do Arco Norte que, no caso de Tabatinga, eram sobrepostos. Essas políticas e programas - e as territorialidades delas decorrentes não divergiram da conformação territorial herdada da colonização e da exploração extrativista e orientaram sobremaneira as políticas públicas desenvolvidas na regiáo nos últimos quinze anos.

Além das políticas brasileiras, Tabatinga cresceu numa relação orgânica com a Colômbia e o Peru. O crescimento de Leticia (Colômbia) e sua consolidação como capital do departamento de Amazonas, como polo turístico e zona de livre comércio, o crescimento e atomização do narcotráfico e a circulação de pessoas e de bens provenientes do Peru contribuíram para a transformação de Tabatinga que, gradativamente, assumiu papel de referência nessa mesorregião no que tange ao acesso a serviços públicos, infraestrutura estatal e comércio. Junto a Leticia e a ilha de Santa Rosa (Peru), a cidade compóe um "complexo urbano transfronteiriço" (Olivar, 2016), que se expande por outras cidades, comunidades e povoados da região nos três países.

De uma primazia absoluta e quase solitária de instituições militares, religiosas e aduaneiras - além de limitadas experiências de exploraçáo econômica dos recursos naturais -, notamos hoje a presença de praticamente todas as instituiçóes do governo federal, estadual e municipal - das quais Cauã e muitos frequentadores do restaurante de Socorro faziam parte. Igualmente, há presença importante de vários agentes civis e religiosos de governamentalidade (ONGs, missóes religiosas diversas, movimentos sociais) e expansão do comércio, das fontes de emprego e da educação, entre outros. De uma ação espetacularizada, fundamentalmente masculina e colonizadora, voltamo-nos para a diversificação e fragmentação das posiçóes de poder em que os agentes locais e femininos ganham proeminência.

\section{Regimes de normatividades de gênero na fronteira}

O processo de expansão do Estado e de transformação territorial sugere, em termos de gênero, 
mudanças importantes no lugar de homens e mulheres no processo de fronteirização e na própria imaginação sobre relaçôes de gênero mobilizada. Em primeiro lugar, resulta evidente que, nos últimos trinta a quarenta anos, houve significativa transformação na participação política e econômica das mulheres nesse processo. Antes marcada sobremaneira pela participação das mulheres nativas na reprodução, na conjugalidade, no cuidado doméstico e, no caso das "forasteiras", na educação escolar infantil, hoje a configuração do Estado nessa fronteira está longe de ser exclusivamente militar e masculina, ainda que homens e militares/policiais continuem tendo destaque quantitativo e simbólico (Melo, 2018).

Muitas mulheres, "forasteiras" e locais, passaram a ocupar cargos de poder e executivos no Estado em diversos âmbitos e níveis. Ainda que existam mulheres em altos cargos de poder governamental, elas ocupam principalmente as responsabilidades politicamente imaginadas como femininas e subsidiárias das políticas de defesa e segurança, como proteção social, direitos humanos, saúde, educação e comunicação. Por outro lado, diversas políticas públicas que operaram nesse território estiveram focadas nas mulheres e previam a garantia de direitos, inclusive a transformação de relações econômicas e de poder. Tal foi o caso da implementação e do fortalecimento nas fronteiras do Sistema Único de Saúde ${ }^{14}$, do Programa Bolsa Família ${ }^{15}$ e das políticas de enfrentamento à violência contra as mulheres (incluindo o combate ao "tráfico de pessoas"), entre outras ${ }^{16}$.

Nesse marco, a ênfase dada à "violência contra as mulheres" (associado à lógica da "vulnerabilidade") como conceito-chave de governamentalidade resulta importante para pensar as novas relaçóes entre fronteira, Estado e gênero. Relatórios da extinta Secretaria de Políticas para as Mulheres da Presidência da República (Brasil, 2014) indicavam que ampla parcela dos recursos dessa pasta foram destinados para açóes de enfrentamento à violência doméstica e familiar. Em cidades fronteiriças como Tabatinga, notamos atenção especial ao combate ao "tráfico de mulheres", o que mobilizou discursos sobre gênero, sexualidade, mobilidade e território muito específicos, conectando uma vez mais as políticas de direitos humanos e proteção social às polí- ticas de segurança pública e defesa nacional, atuando as primeiras como subsidiárias das segundas.

A emergência do discurso sobre "tráfico de pessoas" em Tabatinga estimulou a produção governamental de "denúncias" de tráfico humano - acoplado à "exploração sexual" e à "servidão doméstica" -, que tinham na vigilância a "estrangeiros" e a determinadas sexualidades o seu principal foco. Com efeito, a política de enfrentamento ao tráfico de pessoas ocupou importante lugar na articulação entre gênero e fronteiras, ao estimular açôes de controle da ordem interna (segurança pública) e da ordem externa (defesa nacional), articuladas com uma discursividade governamental humanitarista (Piscitelli, 2016). Contudo, o conhecimento etnográfico da operação dessa política nos permitiu evidenciar o protagonismo das mulheres. Foram fundamentalmente articulaçóes femininas locais, sob uma forte retórica de violência e de reivindicação de direitos, as que demandaram maior presença e maior ação das forças militares e de polícia (masculinas), inclusive para a vigilância das sexualidades e dos deslocamentos das mulheres jovens.

Além do tráfico de pessoas, um fato pontual mostra a maneira como essas novas políticas de mulheres atualizaram e complexificaram a fronteira: o assassinato da radialista tabatinguense Lana Micol Cirino Fonseca (ABI, 2013). Em maio de 2013, a diretora da Rádio Nacional do Alto Solimóes, da Empresa Brasileira de Comunicação, foi alvejada por um motoqueiro desconhecido. Na época, seu ex-marido foi acusado de ser o mandante do crime, cujo processo penal ainda tramita na Justiça brasileira. Sua morte repercutiu nos meios de comunicação e provocou a consternação de moradores da cidade.

$\mathrm{O}$ assassinato trouxe à arena pública divergências e disputas sobre a fronteira, bem como a evidente emergência de um campo local - conectado em redes regionais, nacionais e transfronteiriças preocupado com o gênero, os direitos das mulheres e o feminismo. A princípio, a resposta judicial esteve menos relacionada com as políticas de enfrentamento à violência contra mulheres e mais com o fato de uma servidora federal ter sido morta numa região de fronteira em que mortes por pistolagem são recorrentes (Paiva, 2019). Em momento posterior, lideranças feministas, a Empresa Brasileira de Co- 
municação, a Secretaria de Políticas para Mulheres e a universidade local organizaram manifestações, elaboraram projetos de políticas públicas, promoveram açôes preventivas e exigiram a apuração da morte da radialista como um caso de feminicídio ${ }^{17}$. Mesmo assim, aparentemente deslocando o foco da fronteira, a hipótese do feminismo e do gênero não se furtou da oportunidade de produzir performativamente a nação. $\mathrm{O}$ assassinato resultou, inclusive, na formulação de um projeto nunca implementado de criação da Casa da Mulher Brasileira em Tabatinga ${ }^{18}$. Assim, tanto o assassinato de Lana Micol como a mobilização pública dos discursos de tráfico de pessoas evidenciaram agenciamentos femininos - e feministas - locais em prol de maior e mais coercitiva presença policial e militar (masculina) e de reafirmação da identidade nacional.

Ao concentrarmo-nos analiticamente nas políticas de tráfico de pessoas, de enfrentamento à violência contra mulheres na fronteira, e, finalmente, no caso Lana Micol, almejamos demonstrar as transformaçôes nas relações de gênero, na incorporação e produção do gênero pelo Estado e no modo como os espaços de participação das mulheres em formas de governo e processos de fronteirização diversificaram-se ao longo do processo de formação de Tabatinga, principalmente nos últimos quinze anos. Percebemos também como a força constitutiva das retóricas da violência e da segurança, demandando mais presença estatal e maiores mecanismos de controle, se atualiza e modifica, tendo como base uma nova preocupação de gênero, que insistia em identificar as mulheres locais ora como vítimas, ora como vinculadas a atividades criminais, ora como agentes de "mudança social" e sempre como corpos-nacionais. Mulheres configura-se, pois, um novo espaço de atualização mito-conceitual, que cruza diversos âmbitos de poder e de produçáo de conhecimento.

As abordagens analíticas conectando gênero e territórios de fronteira no Brasil são escassas e têm seu objeto principal nas experiências de mulheres migrantes, deixando de lado conceitualizaçóes de gênero e de fronteira mais relacionais. Algumas delas estão fortemente marcadas por matrizes interpretativas sobre opressão e violência, traduzidas no contexto amazônico como violências sexuais e de gênero contra mulheres e meninas nativas atrela- das a processos de fronteirização interna (Martins, 1997), ou a caraterísticas explícita ou implicitamente tomadas como "culturais" ou "históricas" da região (Torres e Oliveira, 2012). As fronteiras parecem, pois, um bom lugar para atualizar as fantasias e temores sexuais, de gênero, étnicos, nacionais ou regionais (McClintock, 2010).

O revés dessa construção encontra-se em outra desumanização positiva e mitológica das mulheres "amazônidas". Representadas como vítimas da "sexualização" dos "machos demoníacos", das "hostes conquistadoras", são discursivamente reelaboradas como fortes guerreiras e heroínas. O problema é que, como indica Margarita Serje (2005) - e Kamala Kempadoo (2007) para o caso do Caribe -, tais leituras não desativam os mecanismos mito-conceituais e reproduzem os princípios imaginativos sobre esses territórios e seus habitantes.

Todo um universo de princípios e relaçóes de gênero, atravessado pela história e a organização social amazônica, é deixado de lado. Destino semelhante têm práticas e agenciamentos cotidianos, ambíguos e contraditórios, marcados por gênero e lógicas singulares (como as mobilidades, a construção social das geraçôes, as relações com a sexualidade, as relações de trocas econômicas etc.).

Ao avultar a intriga familiar e amorosa entre Socorro, Cauã e Flor, buscamos não apenas observar essa fronteira "desde abajo" (e dali acessarmos outras de suas camadas), mas, sobretudo, experimentar um movimento que nos permitisse desativar esses mecanismos de atualização da forma mito-conceitual, demonstrando como formas de governo espetaculares e cotidianas se imiscuem nos corpos de quem habita aquela fronteira, como na trama de afetos, cuidados e ameaças de nosso trio de personagens que, longe de ser exclusiva ou peculiar, faz parte da miríade de relaçóes de poder que atuam na produção performativa e relacional do gênero e da fronteira.

\section{Reconceitualizando fronteira}

Para o nosso interesse de reconfigurar a fronteira como problema e objeto de estudo pelo viés de uma antropologia do gênero, nos foi de grande 
valor uma produção brasileira recente sobre territórios e relações transfronteiriças. José Lindomar Albuquerque $(2010,2015)$ aborda os limites entre Brasil e Paraguai, materializados nos "brasiguayos". Nesse caso, a fronteira é apresentada como um espaço social em construção através dos agenciamentos diversos de múltiplos atores. Por sua vez, Claudia Lopez (2000) analisa as apropriaçóes e reelaboraçóes que indígenas Ticuna fazem das fronteiras internacionais na produção de um território multifronteiriço ${ }^{19}$. Essa composição de múltiplos territórios e fronteiras, que cruzam frentes de expansão econômica, espaços de contatos interétnicos, limites internacionais e mobilidades transnacionais, adquire força etnográfica e analítica nos textos de José de Souza Martins (1997), Lylia Galetti (2012) e Renata Nóbrega (2016), e marca rumos de análise muito diferentes. Por outro lado, Paula Togni (2014) e Gustavo Dias (2015) mostram como a linha do limite internacional entre o Brasil e a Europa se expande entre os territórios nacionais a partir de tecnologias de controle específicos, como configurações de bairros e em corpos. Nesses trabalhos, produzidos a partir de preciosas etnografias de viagem e de longa duração, se destaca a enorme importância dada aos agentes sociais nas suas práticas e capacidades de produzir, furar, regular, decompor e restituir múltiplas fronteiras. Ademais, em Togni (2014) e Nóbrega (2016) existe uma preocupaçáo explícita - e rara - por compreender essas fronteiras (relações, territórios e deslocamentos) em termos de gênero, afetos, sexualidade, produção de família e circulação econômica.

Outro estudo sugere que "um projeto feminista de fronteiras interroga os múltiplos sentidos dos limites e das fronteiras", e, nesse exercício, Denise Segura e Patricia Zavella (2008, p. 539) propóem quatro dimensóes de análise: estrutural, discursiva, interacional e actancial. As autoras seguem uma tradição chicana/norte-americana de "teoria de fronteiras”, muito inspirada em Glória Anzaldúa (2012) e atenta à produção da identidade, às resistências e hibridizaçóes, às sexualidades "transgressivas" e à semiótica, com forte base disciplinar nos estudos culturais e na crítica literária.

Nossa proposta coincide com o espírito dessa crítica feminista, conectando-a à "virada episte- mológica" dos anos 1980-1990 na antropologia, mobilizada por mulheres e por outras teóricas feministas (Strathern, 1990; Butler, 1990a; Haraway, 1991; Ortner, 1996), além de por outros aportes dos enlaçamentos entre antropologia, história, gênero e narrativa (Sahlins, 1985; Taussig, 1986; McClintock, 2010; Das, 2007). Esse repertório nos ajuda a pensar "o social” (o gênero, as fronteiras) como sistemas de relaçôes e de associaçôes, de práticas de agentes, de tensóes formativas-construtivas, que devem ser reconstruídos e rastreados de forma situada, como o fizemos.

Além disso, exige um olhar entre escalas micro e macro, não como entidades de naturezas diferentes, nem em estrita relação causal, mas como escalas diferentes de redes extensas de agentes sociais (Latour, 2008). Possibilita, dessa forma, uma abordagem mais interessada nas práticas ordinárias de fabricação social do mundo, das diferenciaçóes e distinçóes (McClintock, 2010; Brah, 2006; Piscitelli, 2008), de materialidades e imaginaçóes múltiplas e conectadas parcialmente, do que na lógica espetacular do significado, da dominação e das distinçóes entre simbólico e material, estrutural e discursivo, literal e metafórico, entre outras (Latour, 2008; Wagner, 2010). Como as que observamos nos enunciados de Socorro sobre Flor e de Cauá sobre a abjeção peruana, nos cuidados intercambiados entre comidas e documentos, nas conexóes entre ações de prevenção à violência de gênero e o controle migratório, ou na produção da nação emergida do processo de apuração do assassinato da radialista.

Essa abordagem marca a nossa relação empírica e analítica com o Estado-nação, categoria central nas análises sobre fronteiras. Longe de pensar o Estado-nação como uma entidade que opera sobre a fronteira, optamos por seguir o rumo de uma antropologia preocupada com a reflexão etnográfica sobre governamentalidade e sobre o Estado aqui concebido como sistema administrativo poroso, altamente contingente e polimorfo (Souza Lima, 2002; Das e Poole, 2004; Sharma e Gupta, 2006; Brown, 2010). Prestamos especial atenção à dimensão produtiva e espetacular do Estado na relação com gênero e violências/terror (Das, 2007; Taussig, 1986), com os discursos dos direitos humanos e do 
humanitarismo (Ferreira e Schuch, 2010; Fassin, 2011), e com a regulação do gênero, da sexualidade e dos mercados do sexo (Butler, 2004; Piscitelli, 2016; Vianna, 2012). Nesse enquadramento, a ideia de capilaridade resulta central e será entendida como a própria natureza operacional e criativa do Estado/governamentalidade, seguindo as reflexóes de Michel Foucault sobre governamentalidades e o poder como exercício (Foucault, 2004; Lemke, 2000), bem como a ideia de "atos performativos" de Judith Butler (1990b, 2015) 20 .

Esse conjunto de referências teóricas permite assumir a fronteira como um objeto de estudo etnográfico e antropológico. Optamos conceitualmente por focar numa ideia desqualificada de fronteira como processo (Grimson, 2003), dinâmica (Albuquerque, 2010) e relação - essa última num sentido inspirado por elaboraçóes antropológicas (Strathern, 2014; Viveiros de Castro, 2015). Assim, colocamos a fronteira - aquele "cu do mundo", como costumam afirmar agentes estatais de fronteirização - no "centro do mundo", como processo fortemente corporificado e corporificante, que precisa ser preenchido de dados, perguntas e observações. Nessa lógica, a atenção volta-se às práticas do cotidiano ("to descent into ordinary" [Das, 2007]), às "negociaçôes da intimidade" (Zelizer, 1997), às práticas em jogo, às agências, às micropolíticas das pessoas que habitam e produzem a fronteira dia a dia (Ortner, 1995).

Metodologicamente, nossa proposta esteve centrada no trabalho etnográfico situado $\mathrm{em}$ territórios de fronteira e transfronteiriços, reduzindo o extenso campo semântico e metafórico que comumente conecta estudos de fronteiras. Seguindo a inspiração de autores como Michael Taussig (1986) e Veena Das (2007), os dados etnográficos vêm sendo "reconfigurados", no sentido proposto por Paul Ricoeur (1994) na sua análise sobre memória, tempo, história e narrativa. As descrições assim construídas traduzem, também na forma textual, a mudança de perspectiva e de escala, permitindo iluminar outros aspectos, agenciamentos, relaçóes e, claro, outras fronteiras, como as que nos sugerem a imersão na trama entre Socorro, Cauã e Flor.

Nesse excerto narrativo, vimos os agenciamentos de gênero sendo produzidos, as relaçóes de poder sendo permanentemente negociadas, performatizadas e materializadas nos corpos dos agentes que a produzem. Assim, compreendemos melhor o que está sendo trabalhado e avançamos na análise do governo dessa fronteira por uma perspectiva de gênero. Essa perspectiva foge da narrativa oficial de políticas e agendas de fronteirização, das explicaçóes puramente econômicas e generalizaçóes espetacularizadas e da concepção apriorística da hibridação e da resistência. É outra forma de entender as articulaçôes entre gênero e o governo da fronteira, ou seja, debruçando-se nas suas relaçóes cotidianas ordinárias e de intimidade.

\section{De volta ao começo}

Neste artigo, apresentamos uma rota metodológica e analítica para a compreensão da fronteira e suas formas de governo, pela perspectiva de gênero, influenciada por correntes teóricas da antropologia, dos estudos de gênero e feministas e dos estudos de fronteira. Esse exercício teve vários propósitos: (a) avançar na produção de conhecimento específico sobre um território multi e transfronteiriço e suas formas de governo; (b) argumentar a favor da necessidade de abordagens "from the borderlands"; (c) colocar em discussão a coprodução entre gênero e processos de fronteirização; e (d) apresentar um modo particular de compreender a existência social, afetiva e corporal do Estado-na-fronteira.

Partindo da oposição analítica entre formas de governo ordinárias e espetaculares, revisitamos aqui uma trama afetiva triangulada para, nesse contexto etnográfico, enfatizar alguns aspectos que consideramos importantes. Com isso, propomos uma compreensão das relaçóes entre gênero e fronteira como dinâmicas, inter-relacionadas, multidimensionais e micropolíticas. Nosso argumento principal defende que os processos de fronteirização são altamente definidos por regimes de normatividades de gênero que atualizam, naqueles territórios transfronteiriços, determinadas lógicas de gênero interseccionado à etnia, nação, procedência regional e posição socioeconômica.

Essa imersão no cotidiano contrasta com o agenciamento estatal espetacular, perspectivado na 
segunda parte do artigo. Aqui, empregamos espetacular no mesmo sentido de grandioso, ostentoso e não como sinônimo de extraordinário, posto que intensivamente presente no dia a dia daquela fronteira e imiscuído a ele. Assim, e em consonância com Flávia Melo (2018), compreendemos que o governo espetacular diz respeito tanto à performatividade das operaçóes militares de combate ao tráfico de drogas ou de pessoas, muito frequentes naquela cidade, como ao aparato das forças de segurança e defesa nacional materializado em edificaçóes, veículos e armamentos de grande porte, além de centenas de corpos fardados que por ali circulam diariamente.

Esse par - governo ordinário e governo espetacular - guarda estreita relação com as proposiçóes de Das (2007). Aqui, tratamos justamente de enfatizar como uma forma de governo ostentoso e opulento - portanto, espetacular - se imiscui a outras agências e governamentalidades, é subvertido e reforçado por elas em relaçóes altamente porosas e capilarizadas, tal como observamos. Nesse sentido, aproximamo-nos mais uma vez do modo como Serje (2005) emprega espetacular referindo-se ao projeto nacional, à produção mítica de "a Nação" (pp. 120-138). Com efeito, nosso movimento consistiu, principalmente, em suspender essa perspectiva distanciada e majoritária que chamamos de "o Estado" e indagar etnograficamente pelo que acontece na vida íntima e cotidiana das fronteiras, suas economias, seus universos relacionais e suas arquiteturas de poder e de governo.

Nesse plano de conexóes, acessamos relações como aquelas nas quais Socorro, Cauã e Flor elaboram performativamente posiçóes sociais e de poder (interseccionalmente imbricadas), que têm como efeito a produçáo cotidiana e corporificada da fronteira e de seu governo ordinário que, em Tabatinga, adquire importante densidade social, empírica e actancial. Essa conexão é absolutamente produtiva na tarefa inacabada de montar, explicar e compreender esse lugar, essas relaçóes e fronteiras. Nela, evidenciamos como a mudança de perspectiva é favorecida potencialmente pela mudança da forma do texto. Nesse ir e vir de perspectivas, vemos uma narrativa cujo foco está atento a detalhes da vida íntima dos agentes, a pequenas diferenças e distinções, ao "trabalho do tempo" (Das, 2007), às formas linguísticas provenientes do trabalho de campo, entre outros. Essa atenção implicou uma escrita mais literária, não no sentido das formas poéticas, mas do cuidado narratológico e, portanto, como nos lembra Ricoeur (1994), demanda um tipo de cumplicidade por parte dos leitores, capaz de completar o processo de "reconfiguração" da memória, das narrativas e das relaçôes.

$\mathrm{Na}$ segunda parte do artigo, apresentamos o que pode ser entendido como um ponto de vista sobre "o Estado", o governo espetacular e hegemônico, uma perspectiva fundamentalmente distanciada, abrangente, atenta a fenômenos macroscópicos e a vetores de produção social, cuja base são os centros nacionais de poder, as forças masculinas de desbravamento, os grandes ciclos econômicos. Além disso, a narrativa dessa parte está mais concentrada numa perspectiva histórica, que nos permite construir uma imagem mito-conceitual da fronteira, sobre a qual contrapomos tanto transformaçôes históricas quanto mudanças ou torçốes de perspectiva. Essa imagem resulta de uma imaginação política e nacional sobre gênero e as "terras de ninguém” (Martins, 1997; Nóbrega, 2016), que fez com que fossem apenas homens populares, rurais ou negros (e, em alguns casos, suas mulheres) aqueles que podiam encarar a ação de ponta da expansão agrícola e da defesa nacional. É a imagem mais bruta da "dimensão prerrogativa" do Estado (e da fronteira, e do gênero) como agenciamento masculino (Brown, 2010).

As transformaçōes históricas que evidenciamos em Tabatinga, a partir dos anos 1980, têm a ver com uma expansão da "dimensão liberal" do Estado, com uma nova versão dos processos civilizatórios e de expansão da fronteira interna: o humanitarismo, a assistência social, os direitos humanos, o comércio liberal, as organizaçóes não governamentais. De uma vila militar masculina e suas relações de dominação colonial e de defesa nacional, passamos, em poucos anos, a uma cidade intensa e complexa, referência comercial de uma região transfronteiriça estendida, e com agências ou representantes de praticamente todas as instâncias do Estado em seus diversos âmbitos. Vemos, então, como se faz necessária uma perspectiva diacrônica e processual, atenta à multiplicidade e à transformaçáo, para compreender uma fronteira 
como Tabatinga, suas formas de governo e as relaçóes que gesta.

Nesse cenário, as relações de gênero são produzidas em outros termos e as mulheres ganham espaços de poder e protagonismo em diversos âmbitos de governamentalidade e de comércio. Porém, isso não implica necessariamente uma mudança na perspectiva política sobre as fronteiras (frontiers and borderlands) ou na perspectiva analítica. Nessa lógica, a mulher - e, particularmente, a india -, como sujeito de ação ou como cristalização discursiva, ocupa um lugar central na tensão mítica entre civilização e barbárie. Como parte do mito fundador das açóes de fronteirização, essa posição é visível desde os antigos textos de Domingo Faustino Sarmiento (2010) sobre a frontier argentina. Mulheres nativas ("civilizadas"), mulheres indígenas vinculadas às igrejas ou ao Estado, mulheres "estrangeiras" engajadas em processos de atualização da necessidade nacional de controlar, vigiar e domesticar a fronteira.

Nessa narrativa da perspectiva do Estado, mulheres aparecem com responsabilidade crescente sobre a dimensão humanitária do governo (the care, estruturalmente subordinado ao império da lei), como agentes ativas demandantes de mais proteções e defesas masculinas, e, discursivamente $-a$ Mulher, principalmente indígena e jovem -, como vítima vulnerável requerente de maior tutela ou de mais "empoderamento". Nessa configuração, a necessidade de "integração" ao projeto liberal e desenvolvimentista nacional e a necessidade de "defesa" das ameaças estrangeiras se sobrepóem e tomam forma e força afetiva nos corpos das mulheres.

\section{Notas}

1 Essa narrativa foi construída no percurso de 2016 e tem sido (re)trabalhada, ampliada e aprofundada pelos autores em apresentaçóes orais, palestras e outros textos publicados (Olivar, Melo da Cunha e Rosa 2015; Olivar e Melo da Cunha, 2017).

2 O Acordo de Residência do Mercosul (promulgado pelo Decreto no 6.975/2009) facilitou a migração entre os países do Mercosul, Bolívia e Chile. Peru e Colômbia assinaram o acordo no mesmo ano.

3 Sobre a desqualificação da história sexual indígena; a centralidade do desejo, o erotismo e o prazer sexual na etnologia indígena; e o poder ameaçador da sexualidade feminina indígena, consultar, por exemplo, Belaunde (2015).

4 Magalhães (2015) propóe análise original sobre invejas, traiçóes e feitiços entre mulheres Ticuna. Experimenta caminhos interpretativos que, noutros contextos, inspiram novos enquadramentos para compreender as acusações de feitiço entre mulheres.

5 Importante aspecto concerne às diferentes concepçóes de mestiçagem e indianidade no Brasil, Peru e Colômbia. Sobre as categorias legais de indianidade no Brasil e Peru, ver Reis e Ramos (2018), e na Colômbia, Gros (2010).

6 Decreto-Lei federal no 314/1968 e Lei federal $n^{\circ}$ $5.449 / 1968$.

7 As Forças Armadas Brasileiras permitiram o ingresso de mulheres apenas na década de 1990. Contudo, o serviço militar obrigatório é exclusivo aos homens.

8 Ver os trabalhos de Alvarez (1995), Hannerz (1997), Donnan e Wilson (1999), Faulhaber (2001), García (2003), Albuquerque (2010), Iossifova (2013), Cardin e Colognese (2014) e Olivar (2015).

9 Seguindo a literatura brasileira sobre "frentes de expansão" (Martins, 1997) ou a meta-análise de Faulhaber (2001) e Galetti (2012), entendemos que as análises de Serje resultam perfeitamente úteis para o Brasil.

10 As comunidades Umariaçu I e II encontram-se na Terra Indígena Tukuna Umariaçu, demarcada em 1998 e localizada no município de Tabatinga; tem 5 mil hectares de extensão e população estimada em 7.219 habitantes. Fonte: <https://terrasindigenas.org.br/es/ terras-indigenas/3888>; acesso em: 19 ago. 2019.

11 "A faixa de fronteira do Brasil com os países vizinhos foi estabelecida em $150 \mathrm{~km}$ de largura (Lei $\mathrm{n}^{\circ}$ 6.634/1979), paralela à linha divisória terrestre do território nacional” (Machado et al., 2005, p. 51).

12 O Programa de Promoção do Desenvolvimento da Faixa de Fronteira estabeleceu como "arco norte" o território de "faixa de fronteira" dos estados do Amapá, Pará, Roraima, Amazonas e Acre, na Amazônia Legal brasileira (Brasil, 2009, p. 34).

13 Na Política Nacional de Desenvolvimento Regional (Brasil, 2007), a mesorregião é um "espaço subnacional contínuo, com identidade comum e compreende áreas de um ou mais Estados, definido para identificação de potencialidades e vulnerabilidades que norteiem a formulação de políticas". 
14 A esse respeito, consultar Giovanella et al. (2007) sobre políticas de saúde na fronteira do Arco Sul, decorrentes da ampliação de acordos no Mercosul.

15 Política de transferência condicionada de renda, destinada a famílias em situação de pobreza, similar a outras desenvolvidas na maioria dos países latino-americanos e caribenhos (OIT, 2014).

16 As políticas de enfrentamento à violência contra mulheres estavam vinculadas à extinta Secretaria de Políticas para Mulheres da Presidência da República.

17 Assassinato de mulheres motivado pelo gênero. Acrescentado ao Código Penal Brasileiro pela Lei federal ${ }^{\circ}$ 13104, de 9 de março de 2015.

18 Sobre uma lógica de feminismos carcerários e seu encontro com as políticas humanitaristas no terreno do tráfico internacional de pessoas, ver Bernstein (2010).

19 Para essa abordagem, a noção de "transfronteiriço" (Stephen, 2007; Zárate, 2008; Aponte Motta, 2011) não nos parece suficiente. Em diálogo com Haesbaert (2011), optamos pela imagem de fronteiras múltiplas para pensar em "multiterritorialidades".

20 Em Notes toward a performative theory of assembly, Judith Butler (2015) desloca o conceito de atos performativos do campo do gênero para os seus estudos mais recentes sobre "precariedade", Estado e ação coletiva.

\section{BIBLIOGRAFIA}

ABI - ASSOCIAÇÃO BRASILEIRA DE IMPRENSA. (2003), "Radialista é assassinada em Tabatinga (AM)". Disponível em: <http:// www.abi.org.br/radialista-e-assassinada-em-tabatingaam/>. Acesso em: 23 mar. 2019.

ALBUQUERQUE, José Lindomar. (2010), $A$ dinâmica das fronteiras: os brasiguaios na fronteira entre o Brasil e o Paraguai. São Paulo, Annablume.

ALBUQUERQUE, José Lindomar. (2015), "Procesos de fronterización y sentidos de pertenencia entre Brasil y Paraguay", in A. L. Hernández y A. E. Campos-Delgado (orgs.), Lineas, límites y colindancias. Mirada a las fronteras desde América Latina, Tijuana/Ciudad del México, Colegio de la Frontera Norte/Ciesas.

ALVAREZ, Robert R. (1995), "The Mexican-US border: the making of an anthropology of bor- derlands". Annual Review of Anthropology, 24: 447-470.

ANZALDÚA, Gloria. (2012), Borderlandslla frontera: the new mestiza. San Francisco, Aunt Lute Books.

APONTE MOTTA, Jorge. (2011), Leticia y Tabatinga: transformación de un espacio urbano en la Amazonia. Tesis de maestría, Leticia, Universidad Nacional de Colombia.

BECKER, Bertha. (2005), "Geopolítica da Amazônia”. Estudos Avançados, 19 (53): 71-86.

BELAUNDE, Luisa Elvira. (2015), "O estudo da sexualidade na etnologia", Cadernos de Campo, 24 (24): 399-411.

BERNSTEIN, Elizabeth. (2010), "Militarized humanitarism meets carceral feminism: the politics of sex, rights, and freedom in contemporary antitrafficking campaigns". Signs: Journal of women in culture and society, 36 (1): 45-71.

BRAH, Avtar. (2006), "Diferença, diversidade, diferenciação". Cadernos Pagu, 26: 329-376.

BRASIL. MINISTÉRIO DA INTEGRAÇÃO NACIONAL. (2009), Programa de Promoçãa do Desenvolvimento da Faixa de Fronteira. Disponivel em: <http://ois.sebrae.com.br/publicacoes/2970-2/>. Acesso em: 19 ago. 2019.

BRASIL. PRESIDÊNCIA DA REPÚBLICA. (2007), Politica Nacional de Desenvolvimento Regional. Decreto no 6.047, de 22 de fevereiro de 2007. Disponível em: <http://www.planalto.gov.br/ccivil_03/_Ato2007-2010/2007/Decreto/D6047.htm>. Acesso em: 19 ago. 2019.

BRASIL. PRESIDÊNCIA DA REPUUBLICA. (2008), Programa Territórios da Cidadania. Brasília, DF.

BRASIL. PRESIDÊNCIA DA REPÚBLICA. Secretaria de Políticas para as Mulheres. (2014), Relatório de Gestão 2011-2014. Disponível em: <http://www.consultaesic.cgu.gov.br/busca/dados/Lists/Pedido/Attachments/430130/RESPOSTA_RECURSO_1_RelatrioGesto.pdf $>$. Acesso em: 23 mar. 2019.

BROWN, Wendy. (2010), "Finding the men in the State", in A. Sharma and A. Gupta (orgs.), The anthropology of the State - a reader, Oxford, Blackwell.

BUTLER, Judith. (1990a), Gender trouble: femi- 
nism and the subversion of identity. New York/ London, Routledge.

BUTLER, Judith. (1990b), "Performative acts and gender constitution: an essay in phenomenology and feminist theory", in S. Case, Performing feminisms: feminist critical theory and theory, New York, John Hopkins University Press.

BUTLER, Judith. (2004), Gender regulations. Undoing gender. New York/London, Routledge.

BUTLER, Judith. (2015), Notes toward a performative theory of assembly. Cambridge/London, Harvard University Press.

CAMACHO, Roberto Piñeda. (2011), "El río de la mar dulce. Imaginarios sobre la amazonia: los dilemas entre un paraíso y un infierno verde", in J. A. Echeverri y C. P. Niño (orgs.), Amazonia colombiana: imaginarios y realidades, Bogotá, Universidad Nacional de Colombia.

CAMPOS, Ana Maria de Mello. (2018), O parto na fronteira amazônica Brasil e Peru: etnografia sobre a assistência obstétrica no município de Benjamin Constant / Amazonas. Dissertação de mestrado, Manaus, UFAM.

CARDIN, Eric Gustavo \& COLOGNESE, Silvio Antonio. (orgs.) (2014), As ciências sociais nas fronteiras: teorias e metodologias de pesquisa. Cascavel, PR, Gráfica JB.

COUTO, Mia. (2005), O último voo do flamingo. São Paulo, Companhia das Letras.

DAS, Veena. (2007), Life and words: violence and the descent into the ordinary. Berkeley, University of California Press.

DAS, Veena \& POOLE, Deborah. (2004), Anthropology in the margins of the State. Santa Fe, SAR Press.

DIAS, Gustavo. (2015), “Tactics of border crossing movement: exploring the mobility of Brazilians through the Schengen and UK airspace". Ambivalências, São Cristóvão, UFS, 3 (5): 216247.

DONNAN, Hastings \& WILSON, Thomas M. (1999), Borders: frontiers of identity, Nation and State. Oxford, Berg.

FALQUINA, Silvia Martínez. (2003), Indias y fronteras: el discurso en torno a la mujer étnica. Oviedo, Ediciones KRK.

FASSIN, Didier. (2011), Humanitarian reason: a moral history of the present. Berkeley, University of California Press.

FAULHABER, Priscila. (2001), "A fronteira na antropologia social: as diferentes faces de um problema”. BIB, 51: 105-125.

FERREIRA, Jaqueline \& SCHUCH, Patrice. (2010), Direitos e ajuda humanitária: perspectivas sobre família, gênero e saúde. Rio de Janeiro, Editora da Fiocruz.

FOUCAULT, M. (2004), Nascimento da biopolitica. São Paulo, Martins Fontes.

GALETTI, Lylia da Silva Guedes. (2012), Sertão, fronteira, Brasil: imagens de Mato Grosso no mapa da civilização. Cuiabá, Entrelinhas/EdUFMT.

GARCÍA, Clara Inés. (org.) (2003), Fronteras: territorios y metáforas. Medellín, Hombre Nuevo Editores.

GIOVANELLA, Ligia et al. (2007), "Saúde nas fronteiras: acesso e demandas de estrangeiros e brasileiros não residentes ao SUS nas cidades de fronteira com países do Mercosul na perspectiva dos secretários municipais de saúde". Cadernos de Saúde Pública, 23 (2): 251-266.

GRIMSON, Alejandro. (2003), "Los procesos de fronterización: flujos, redes e historicidad", in C. I. García (org.), Fronteras: territorios y metáforas. Medellín, Hombre Nuevo Editores.

GROS, Christian. (2010), Nación, identidad y violencia: el desafío latinoamericano. Bogotá, Universidad Nacional de Colombia/Universidad de Los Andes.

HAESBAERT, Rogério. (2011), "Multi/transterritorialidade e contornamento: do trânsito por múltiplos territórios ao contorno dos limites fronteiriços", in N. Fraga (org.), Territórios e fronteiras: (re)arranjos e perspectivas, Florianópolis, Editora Insular.

HANNERZ, Ulf. (1997), "Fluxos, fronteiras, híbridos: palavras-chave da antropologia transnacional". Mana, 3 (1): 7-39.

HARAWAY, Donna. (1991), Simians, cyborgs, and women. The reinvention of nature. Routledge, New York.

HARVEY, David. (2004), Espaços de esperança. São Paulo, Loyola.

HARVEY, David. (2006), Spaces of global capita- 
lism: towards a theory of uneven geographical development. London/New York, Verso.

IBGE. CENSO DEMOGRÁFICO 2018. Disponível em: <https:/cidades.ibge.gov.br/brasil/am/ tabatinga/panorama>. Acesso em: 19 ago. 2019.

IOSSIFOVA, Deljana. (2013), "Editorial. Searching for common ground: urban borderlands in a world of borders and boundaries". Cities, 34: $1-5$.

KEMPADOO, Kamala. (2007), "The war on human trafficking in the Caribbean". Race and Class, 49 (2): 79-84.

LASMAR, Cristiane. (2004), De volta ao lago de leite. São Paulo, Editora da Unesp/ISA/NuTI.

LATOUR, Bruno. (2008), Reensamblando lo social: una introducción a la teoría del actor-red. Buenos Aires, Manantial.

LEMKE, Thomas. (2000), "Foucault, governmentality, and critique". Disponível em: <http:// www.thomaslemkeweb.de/publikationen/Foucault, \%20Governmentality, \%20and\%20Critique\%20IV-2.pdf>. Acesso em: 23 mar. 2019.

LOPEZ, Claudia. (2000), Ticunas brasileros, colombianos y peruanos: etnicidad y nacionalidad en la región de fronteras del alto Amazonas/Solimóes. Tese de doutorado, Brasília, UnB.

MACHADO, Lia Osorio et al. (2005), "O desenvolvimento da faixa de fronteira: uma proposta conceitual-metodológica”. Disponível em: $<$ https://www.academia.edu/1963113/O_Desenvolvimento_da_Faixa_de_Fronteira_uma_ proposta_conceitual-metodol\%C3\%B3gica>. Acesso em: 23 mar. 2019.

MAGALHÃES, Aline Moreira. (2015), "Mulheres ciumentas, homens enfeitiçados: contribuições Ticuna para as reflexóes sobre gênero e violência", Cadernos de Campo, 24 (24): 465-486.

MARQUES, Adriana Aparecida. (2007), Amazônia: pensamento e presença militar. Tese de doutorado, São Paulo, FFLCH-USP.

MARTINS, José de Souza. (1997), Fronteira: a degradação do outro nos confins do humano. São Paulo, Hucitec.

MCCLINTOCK, Anne. (2010), Couro imperial: raça, gênero e sexualidade no embate colonial, Campinas, Edunicamp.

MELO, Flávia. (2018), "Pena e perigo no governo da fronteira: consideraçóes para uma análise generificada da fronteira amazônica de Brasil, Peru e Colômbia”. Revista de Ciências Sociais, Fortaleza, UFC, 49 (3): 201-242.

MELO, Flávia. (2019), "Mover-se nas fronteiras: percursos, políticas e saberes transfronteiriços". Revista de @ntropologia da UFSCar, 11(1): 599-622.

MORENO, Juana Valentina Nieto \& LANGDON, Esther Jean. (2018), "Narrativas de violencia y transformación de mujeres indígenas Uitoto en Bogotá", Revista Abya Yala, 2 (2):140-177.

NAIL, Thomas. (2016), Theory of the border. New York, Oxford University Press.

NÓBREGA, Renata. (2016), "Entra na Roda": história, cotidiano e mobilidades em Rondônia. Dissertação de mestrado, Campinas, Unicamp. OIT - Organização Internacional do Trabalho. (2014), World social protection report-2014/15: building economic recovery, inclusive development and social justice. Disponível em: <http:// www.ilo.org/wcmsp5/groups/public/---dgreports/---dcomm/documents/publication/ wcms_245201.pdf>. Acesso em: 19 ago. 2019.

OLIVAR, Jose Miguel Nieto. (2015), "Performatividades governamentais de fronteira: a produção do Estado e da fronteira através das políticas de tráfico de pessoas na Amazônia brasileira”. Ambivalências, São Cristóvão, UFS, 3: 149-182.

OLIVAR, Jose Miguel Nieto. (2016), “Exploring traffic and exploitation on the Brazilian international border in the Amazon". Social and Economic Studies, 65: 57-86.

OLIVAR, Jose Miguel Nieto \& MELO DA CUNHA, Flávia. (2017), "Gender, narratives and perspectives: notes toward an anthropological understanding of government on the border between Brazil, Peru and Colombia”. Eurasia Border Review, 8: 87-108.

OLIVAR, Jose Miguel Nieto; MELO DA CUNHA, Flávia \& ROSA, Patricia Carvalho. (2015), "Presenças e mobilidades transfronteiriças entre Brasil, Peru e Colômbia: o caso da 'migração' peruana na Amazônia brasileira”. Tomo, São Cristóvão, UFS, 26: 123-163.

ORTNER, Sherry. (1995), "Resistance and the 
problem of ethnographic refusal". Comparative Studies in Society and History, 37 (1): 173-193. ORTNER, Sherry. (1996), "Gender hegemonies", in S. Ortner (1996), Making gender: the politics and erotics of culture. New Jersey, Beacon Press. PAIVA, Luiz Fabio Silva. (2019), “As dinâmicas do mercado ilegal de cocaína na tríplice fronteira entre Brasil, Peru e Colômbia”, RBCS, 34 (99): $1-19$.

PEREIRA, Pedro Paulo Gomes. (2010), "Violência, gênero e cotidiano: o trabalho de Veena Das", Cadernos Pagu, 35: 357-369.

PISCITELLI, Adriana. (2008), "Interseccionalidades, categorias de articulação e experiências de migrantes brasileiras". Sociedade e Cultura, 11 (2): 263-274.

PISCITELLI, Adriana. (2016), "Economias sexuais, amor e tráfico de pessoas - novas questôes conceituais". Cadernos Pagu [online], 47.

REIS, Rodrigo Oliveira Braga \& RAMOS, Ana Sávia Farias. (2018), “Direitos territoriais dos povos indígenas: um estudo comparado sobre o Brasil e o Peru", Revista Eletrônica OABRJ, Ediçâo especial Direitos e Povos Indígenas, 9: 1-22.

RICOEUR, Paul. (1994), Tempo e narrativa. Campinas, Papirus.

SAHLINS, Marshall. (1985), Islands of history. Chicago, University of Chicago Press.

SAMPAIO, Patricia Melo. (2009), "Amazônia: fronteiras, identidades e história". Ciência e Cultura, 61 (3): 26-29.

SARMIENTO, Domingos Faustino. (2010), Facundo ou civilização e barbárie. São Paulo, Cosac Naify.

SEGURA, Denise \& ZAVELLA, Patricia. (2008), "Introduction: gendered borderlands". Gender \& Society, 22 (5): 537-544.

SERJE, Margarita. (2005), El revés de la nación: territorios salvajes, fronteras y tierras de nadie. Bogotá, Universidad de los Andes.

SHARMA, Aradhana \& GUPTA, Akhil. (2006), "Introduction: Rethinking theories of the State in an age of globalization", in A. Sharma and A. Gupta, The Anthropology of the State: a reader, Oxford, Blackwell.

SOUZA LIMA, Antonio Carlos. (2002) "Sobre gestar e gerir a desigualdade: pontos de inves- tigação e diálogo", in A. C. Souza Lima (org.), Gestar e gerir: estudos para uma antropologia da administração pública no Brasil. Rio de Janeiro, Relume Dumará.

SPRANDEL, Marcia Anita. (2005), "Breve genealogia sobre os estudos de fronteiras \& limites no Brasil", in R. Cardoso de Oliveira and S. Baines (orgs.), Nacionalidade e etnicidade em fronteiras, Brasília, UNB.

STEPHEN, Lynn. (2007), Transborder lives: indigenous Oaxacans in México, California and Oregon. Durham/London, Duke University Press.

STRATHERN, Marilyn. (1990), The gender of the gift: problems with women and problems with society in Melanesia. Berkeley/Los Angeles, University of California Press.

STRATHERN, Marilyn. (2014), O efeito etnográfico e outros ensaios. São Paulo, Cosac Naify.

TAUSSIG, Michael. (1986), Shamanism, colonialism and the wild man: a study in terror and healing. Chicago, University of Chicago Press.

TOGNI, Paula. (2014), A Europa é o CACÉM. Mobilidades, gênero e sexualidade nos deslocamentos de jovens brasileiros para Portugal. Tese de doutorado, Lisboa, Universidade de Lisboa.

TORRES, Iraildes Caldas \& OLIVEIRA, Marcia Maria. (2012), Tráfico de mulheres na Amazônia. Florianópolis, Editora Mulheres.

VIANNA, Adriana. (2012), "Atos, sujeitos e enunciados dissonantes: algumas notas sobre a construção dos direitos sexuais", in R. Miskolci and L. Pelucio (orgs.), Discursos fora da ordem: sexualidades, saberes e direitos, São Paulo, Fapesp/ Annablume.

VIVEIROS DE CASTRO, Eduardo. (2015), Metafísicas canibais: elementos para uma antropologia pós-estrutural. São Paulo, Cosac Naify.

WAGNER, Roy. (2010), A invenção da cultura. São Paulo, Cosac Naify.

ZÁRATE, Carlos Botia. (2008), Silvícolas, siringueros y agentes estatales: el surgimiento de una sociedad transfronteriza en la amazonia de Brasil, Perú y Colombia, 1880-1932. Leticia, Universidad Nacional de Colombia.

ZELIZER, Viviane. (1997), The purchase of intimacy. Princeton, Princeton University Press. 


\section{O ORDINÁRIO E O ESPETÁCULO NO GOVERNO DA FRONTEIRA: NORMATIVIDADES DE GÊNERO EM TABATINGA}

\author{
Flávia Melo e José Miguel Nieto Olivar
}

Palavras-chave: Antropologia; Estado; Governamentalidade; Amazônia.

Este trabalho advém de experiência etnográfica na cidade de Tabatinga (AM), tríplice fronteira de Brasil, Peru e Colômbia. Interessa-nos compreender como "o Estado" e "a fronteira" se emaranham, são construídos e apropriados por redes locais afetivas, econômicas, sexuais e familiares, levando em consideração uma perspectiva teórica de gênero. A partir da trama de afetos de uma tríade de personagens que colocam em cena uma forma ordinária de governo, propomos uma análise diacrônica de governamentalidades masculinas espetaculares, que atualizam certo mito-conceito de fronteira. Esse caminho nos conduz à análise da ampliação da participação das mulheres, e da vida social de políticas públicas que mobilizam a categoria mulher, situacionalmente associada à regiāo fronteiriça. Por fim, rumamos a uma reconceitualizaçáo de fronteira por uma perspectiva relacional e processual, na qual gênero, como elaboração performativa e interseccional, tem lugar central.

\section{THE ORDINARY AND THE SPECTACLE IN BORDER GOVERNMENT: GENDER NORMATIVITY IN TABATINGA}

\section{Flávia Melo e José Miguel Nieto Olivar}

Keywords: Anthropology; State; Governmentality; Amazon

This paper arises from ethnographic experience in the city of Tabatinga (AM), place of the triple border of Brazil, Peru and Colombia. We concern ourselves with comprehending the entanglement between "State" and "border", how they are constructed and appropriated by local emotional, economic, sexual and familiar networks, standing from the perspective of gender theory. Starting from the web of affections of three characters who put in place an ordinary form of government, we offer a diachronic analysis of spectacular male governmentalities, which updates a specific myth-concept of border. This path takes us to the analysis of the widening of women's participation and of the social life of public policies that mobilize the category "woman", situationally associated with the border region. At last, we move towards a reconceptualization of border through a relational and processual perspective, in which gender, as an intersectional and performative construct, has a central place.

\section{LE BANAL ET LE SPECTACLE DANS LE GOVERNEMENT DE LA FRONTIËRE: NORMATIVITÉS DE GENRE À TABATINGA}

Flávia Melo et José Miguel Nieto Olivar

Mots-clés: Anthropologie; État; Gouvernementalité; Amazonie.

Ce travail provient d'une expérience ethnographique dans la ville de Tabatinga (AM), dans la triple frontière entre le Brésil, le Pérou et la Colombie. Nous nous sommes intéressés à comprendre comment "l'État » et " la frontière " s'enchevêtrent, sont construits et appropriés par des réseaux locaux affectifs, économiques, sexuels et familiaux, en tenant compte d'une perspective théorique du genre. A partir de l'intrigue d'affections d'une triade de personnages qui mettent en scène une forme banale de gouvernement, nous proposons une analyse diachronique des gouvernementalités masculines spectaculaires, qui mettent à jour un certain mythe-concept de frontière. Cette voie nous conduit à l'analyse de l'expansion de la participation des femmes et de la vie sociale des politiques publiques qui mobilisent la catégorie des femmes et est associée, du point de vue situationnel, à la région frontalière. En conclusion, nous proposons une reconceptualisation de la frontière d'un point de vue relationnel et procédural, dans laquelle le genre, comme l'élaboration performative et intersectionnelle, occupe une place centrale. 